\title{
Smart Grid and Renewable for Energy Security in China
}

\author{
Chun Sing Lai, \\ Student MIEEE \\ Energy and Power Group \\ University of Oxford \\ Oxfordshire, UK \\ chun.lai@eng.ox.ac.uk
}

\author{
Loi Lei Lai, \\ Fellow IEEE \\ State Grid Energy Research Institute \\ Beijing, China \\ lailaili@sgeri.sgec.com.cn
}

\begin{abstract}
This paper presents few key issues that must be taken into account for energy system development and planning. Discussions on energy efficiency, renewables deployment and energy policy are required to improve energy security of any countries. Some figures in China will be used to demonstrate the proposed ideas. Some novel strategies and methods will be discussed. An example on demand response will be included.
\end{abstract}

Index Terms - Smart grid, clean energy, energy security, power system planning, demand response

\section{INTRODUCTION}

Under deregulation and competition in the electric power industry, new ways are being searched to improve the efficiency of the network and reduce energy trading risk without seriously diminishing its reliability and security [1].

How to control a highly distributed, yet highly interconnected system is a serious technological problem [2, $3]$. It is even more complex and difficult to control, operate and manage it for optimal efficiency and maximum benefit to the ultimate consumers while still allowing all its business components to compete fairly and freely. Naturally, it aims to have a secure, manageable, affordable, renewable and technological advanced system. This paper presented an some of the key impacts due to environmental, social, economic and technological issues and the context in which the electricity infrastructure is being operated under the above issues; a smart grid would enable more secure and robust systems operation, security monitoring and efficient energy markets but cyber-attack must be minimized for a success. Renewables and clean energy will be considered how they could improve energy security in China.

\section{ENERGY EFFICIENCY}

A key point for energy security goal of reducing oil imports is to improve the efficiency of its domestic energy markets by accelerating pricing, regulatory and other reforms
[4]. China is actively looking for smart energy technology. Energy efficient technologies often represent upgrades in service through superior performance, for example, improved reliability of service through greater ability of utilities to respond to time of peak demand. So these innovations can provide a better and less expensive service. Some strategies for microgrids and demand response in residential area will be looked at later in the paper.

The public also predominantly believes that the need to cut down on energy consumption and protect the environment means increased energy efficiency should be mandated for certain products. There are main tasks that must be pushed for such as securing leadership in clean energy technologies; maintaining economic prosperity with clear leadership in strategic areas and establishing an operational \& adaptable framework to maximize the success.

Through improvements to the processes of monitoring and coordinating the generation, transmission, and distribution of energy, opportunities for energy loss reduction may be found in utility, industrial, commercial, and residential areas through power system data acquisition and control; automatic generation control; load and energy management; distribution generation; and real-time energy pricing. Long distance power transmission results in energy loss. These losses were estimated at $7 \%$ or so. Energy generation and distribution can be more efficient the closer it is to the point of use, if conducted in a high-efficiency generator. Distributed generation is a means of reducing total and transmission and distribution losses [2].

China is undertaking substantial long distance transmission projects with record breaking capacities, and has the goal of achieving an integrated nationwide grid in the period between 2015 and 2020. With the advent of Flexible AC Transmission Systems (FACTS) technology a new possibility of optimizing the power flow without resorting to generation rescheduling or topology changes has arisen. Unified Power Flow Controller (UPFC) the most advanced in the family of these devices can provide a lot of flexibility in Optimal Power 
Flow (OPF) by injecting a controlled series and shunt compensation. Proper coordination of the UPFC with the existing on-load tap changer (OLTC) transformers already present in the system will certainly improve the steady state operating limit of any power system. An 'optimal' location and parameters of an UPFC along with values of OLTC taps could be determined to minimize the real power losses of a power network [5].

\section{CYBER SECURITY}

Although deploying the smart grid has enormous social and technical benefits, several security and privacy concerns arise. Smart meters have unintended consequences for customer privacy. Energy use information stored at the meter and distributed may expose customer habits and behaviors. Moreover, because grid customers are connected over a large network of computerized meters and infrastructure, they and the infrastructure itself become vulnerable to attacks.

There is a need to develop methods and plans to protect power systems against effects of attacks against critical elements of the energy infrastructure, bringing detailed knowledge of key infrastructures and interdependencies; processes to assess threats and vulnerabilities and develop risk management programs; methods to integrate new technologies and systems to improve reliability in advanced communication protocols; and visualization \& decision support, including mitigation strategies. Security measures are designed to protect the electrical grid from attacks by terrorists and hackers. Naturally, in every country, security is a major policy priority.

To handle the growing demands for residential customers participating smart load managements with motivation from governments, potentially huge numbers (hundreds of thousands) of network-capable intelligent electronic devices (IEDs) could be connected to the distribution system's supervisory control and data acquisition (SCADA) network. These IEDs could be utilized by cyber-attackers to disrupt the distribution system operations, e.g. disrupting power flow in the smart grids, or to defraud the distribution system of revenue, e.g. altering energy consumption records.

An important application for these IEDs is the interaction amongst the utilities, consumers, and distributed resources within the smart distribution system. With implementation of deregulation and open-access-to-utility policies, there will be an increasing amount of small-scale collaborative electricity generations in the smart distribution systems for supplying industrial loads, and there will be a rapidly increasing number of micro-scale distributed generations from renewable energy sources in residential areas, that eventually represents a significant generation pool in the smart distribution system. The electricity distributed generations can be coordinated through IED communication to enhance electricity supplies with most cost-effective and environment-friendly, and to minimize power disruptions due to mismatched operations with the utility systems.

The trend for open system environments, as well as the evolution of communication and substation automation applications toward the usage of standardized components, have broken down inherent security barriers that earlier were created by proprietary solutions. Therefore, from a cybersecurity perspective, insecurity in one part could, and probably would, affect other part of the power system. The power utilities are increasingly facing with security threats from a wide range of sources. Furthermore, as many applications of monitoring and controlling within power utilities operate upon dedicated network, there are many more machines connected to the network. While the existence of a machine on the network with a modem attached to it can still open the system to a dangerous attack. There are traditional technologies, such as digital signature and digital certificates, can be used to guarantee data integrity. It is prudent to recognize that any security mechanisms may be imperfect and may fail. Consequently, designs should employ multiple, diverse so that attacks that exploit the failure of one mechanism will be stopped by a different one. Based on the IEC 61850 standard, a substation host station can communicate to collect measurements from IEDs throughout the substation, and it may identify and reject the fake data, block the highly suspicious tripping signals. It is also important to operate the system even when the network fails for communication congestion or other reasons.

\section{SMART GRIDS}

Smart grids are networks that monitor and manage the transport of electricity from all generation sources to meet the varying electricity demands of end users [6, 7]. They are, and will continue to be, deployed at different rates in a variety of settings around the world, depending on local commercial attractiveness, compatibility with existing technologies, regulatory developments and investment frameworks.

The widespread deployment of smart grids is crucial to achieving a more secure and sustainable energy future. As well as addressing current concerns with existing electricity systems, such as ageing infrastructure and increasing peak demand, smart grids are an important element for expanding the use of a number of low-carbon technologies, including electric vehicles and 'variable' renewables such as wind, solar PV, tidal, and wave generation [8].

Traditionally, utilities concentrated on optimizing themselves as mainly commodity focused businesses, with objectives focused on cost minimization and reliable provision of energy. The new smart power system will require other capabilities that will allow smart technologies to fulfill their true potential. For example, consumer and network data from smart grid will require capabilities in data management, customer relationship management, analytics, etc. Telecommunications have started entering the utility market, developing new and innovative smart grid capabilities. New entrants provide both competition and opportunity to the existing members of the value chain. In the competitive retail sector, there is the potential for specialist new entrants to offer new energy management products and services to consumers. The role of communications in smart 
grid that represents a significant contribution to the capital expenditure and operating expenditure means that communication will likely play a significantly increasing role in the smart grid value chain. Information and Communications Technology (ICT) players will support smart grid through innovations.

When failures occur at various locations in such a network, the whole system breaks into isolated islands. With the intelligence distributed, and the components acting independently, those in each island have the ability to reorganize themselves and make efficient use of available local resources until they are able to rejoin the network.

Expenditures could be linked to outcomes achieved on network reliability, safety, environmental targets, customer satisfaction and social objectives. It has been claim that time synchronization is now critical to the smart grid, with substations using legacy systems and new standards for network time synchronization [9].

For distributed generation cases, a novel infrastructure is shown in Figure 1 below to have many microgrid systems which will overcome issues associated with high level penetration of renewable energy sources and electric vehicles. The new strategy is that with the interconnection of a number of microgrids, the sharing of power generation and demand will improve electricity supply stability and security.

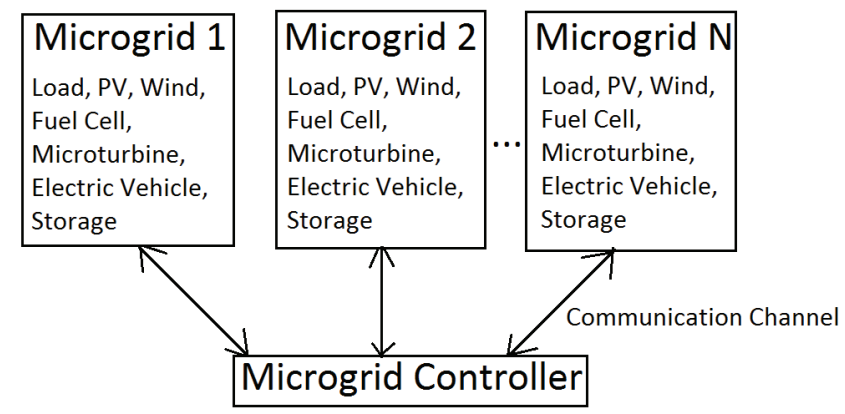

Figure 1. Infrastructure of microgrids coordination

The microgrid operates under constraints such as the level of discharge the energy storage, the start-up time and shutdown time of each energy resource, different pricing scheme and power quality [10] \& losses. Voltage and current waveforms are often used for trouble-shooting Processing data in a standalone manner is not enough. Methods are needed to reduce the difficulty to combine knowledge with Big Data analytics

Each microgrid based on the information on the load demand, pricing, peak value and network congestion achieves minimum line losses and maximum operating system efficiency. This novel approach has a good potential to replace the undesired load shedding technique employed in the existing microgrid systems. With this good practice, it is foreseen that it is feasible to promote the replacement of carbon intensive generation with renewable generation in a large scale and it leads to a significant impact for a cleaner environment.
Smart meters and two-way communications enable the penetration of demand response into smart grids, which leverage the information and communication technologies to achieve efficient and economical power generation, distribution and utilization. At the core of innovative smart grid technologies, demand response faces specific technical issues worth exploring, such as price uncertainty, renewable generation, energy storage etc. Power consumers receive price information through smart meter. With this information, power consumers make or update their consuming plan so as to increase their efficiency by economic incentive. At present, static price is the most traditional power tariff. All electricity is sold under the same price value.

Figure 2 shows the comparison between normalized load constructed from a survey and the normalized load from a city in China under static price scheme. The load curve from practice is smoother as it contains more samples.

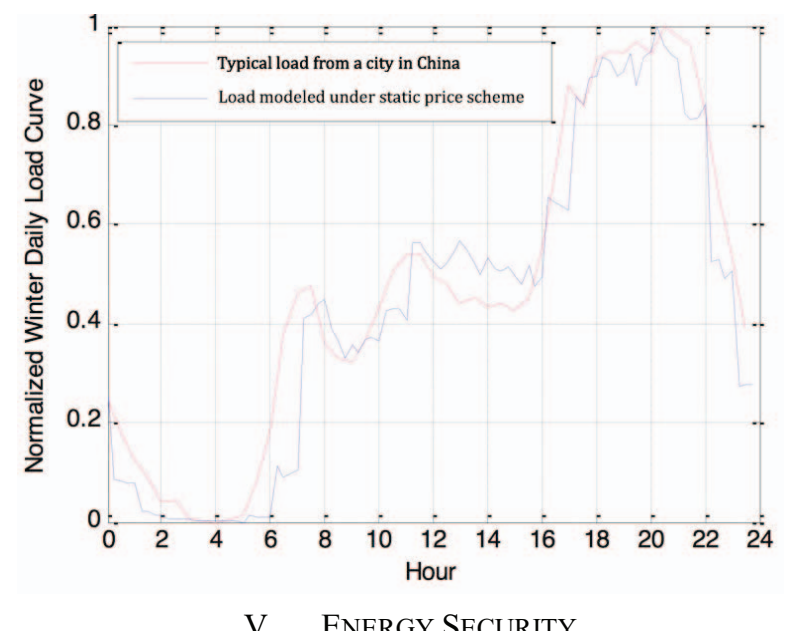

Energy security, as mentioned before, refers to the uninterrupted availability of energy sources at an affordable price $[11,12]$. The need to increase energy security was the main objective in the establishment of the IEA in 1974. IEA was created to establish effective mechanisms for the implementation of policies across a broad spectrum of energy issues: mechanisms that were workable and reliable, and could be implemented in a cooperative manner.

Long-term energy security is mainly linked to timely investments to supply energy in line with economic developments and environmental needs. On the other hand, short-term energy security focuses on the ability of the energy system to react promptly to sudden changes in the supplydemand balance.

Security of energy supply has gained importance on the policy agenda due to the growing dependence of industrialized economies on energy consumption and the increased frequency of supply disruption. Security of electric energy includes transportation of primary energy sources, generation, transmission, distribution and supply of energy for securing of life of the society under the technical, economical, socio-political and environmental point of view. 
Threats to energy security include the political instability of energy producing countries, the manipulation of energy supplies, the competition over energy sources, attacks on supply infrastructure, as well as accidents, natural disasters and rising terrorism. The political and economic instability caused by war or other factors such as strike action can also prevent the energy industry from a proper functioning.

There are measures to increase energy security by reducing dependence on any one source of imported energy, increasing the number of suppliers, exploiting renewable energy resources, and reducing overall demand through energy conservation measures. It can also involve entering into international agreements to underpin international energy trading relationships such as the recent signed agreement between China and Russia in oil transportations. Increasing energy security is one of the reasons behind greater investment in native renewable energy technologies and energy conservation. Different approaches are used for assessing security of energy supply: geopolitical assessment of scenarios, economical modeling, risk assessment, analysis of primary energy sources, and development of security indicator system.

\section{ENERGY SECURITY IN CHINA}

According to State Grid Corporation of China, in 2020, $1000 \mathrm{kV}$ UHV will become the construction goal of grid backbone and backbone channel of power transmission with large capacity, across long distance and large area networks. $\pm 800 \mathrm{kV}$ DC transmission level will become the main network of large hydropower bases in western China and large coal bases in ultra-high capacity. By 2020, overall sending power capacity of Shanxi, Shanxi, Inner Mongolia and Ningxia regions and Central China Power Grid can reach 186.8 million $\mathrm{kW}$ and sending energy capacity will be about 792.3 billion $\mathrm{kWh}$.

From the situation of primary energy supply and demand in the future and participation of international energy competition and trade, in a situation of high proportion of coal consumption and increasing dependence on foreign oil and gas energy supply, energy security will face serious challenges on the clean energy supply, energy price stability, energy production security and promotion of environmental protection. The challenges of reducing carbon emissions and ensuring security of supply are closely linked. China still mainly relies on coal for electricity. China is first in the world in both coal production and consumption, which has sparked environmental concerns. In order to achieve environmental targets in combating pollution and global warming, China must ultimately improve its coal efficiency and switch to alternative energy sources [13].

China is the world's leading renewable energy producer, with an installed capacity of $152 \mathrm{GW}$. China is also the largest producer of wind turbines and solar panels. Approximately $7 \%$ of China's energy was from renewable sources in 2006 , a figure targeted to rise to $16 \%$ by 2020 . The major renewable energy source in China is hydropower. China already has the most hydro-electric capacity in the world, and the Three Gorges Dam with a total capacity of 22.5 GW. It has been in full operation since May 2012.

The Western areas are rich in solar power resources. The sunshine time in $2 / 3$ of the land has more than 2200 hours annually. Since the load is mainly focused in the eastern and southern areas, therefore long distance transmission system is required for planning. Figure 3 shows the annual utilization hours.

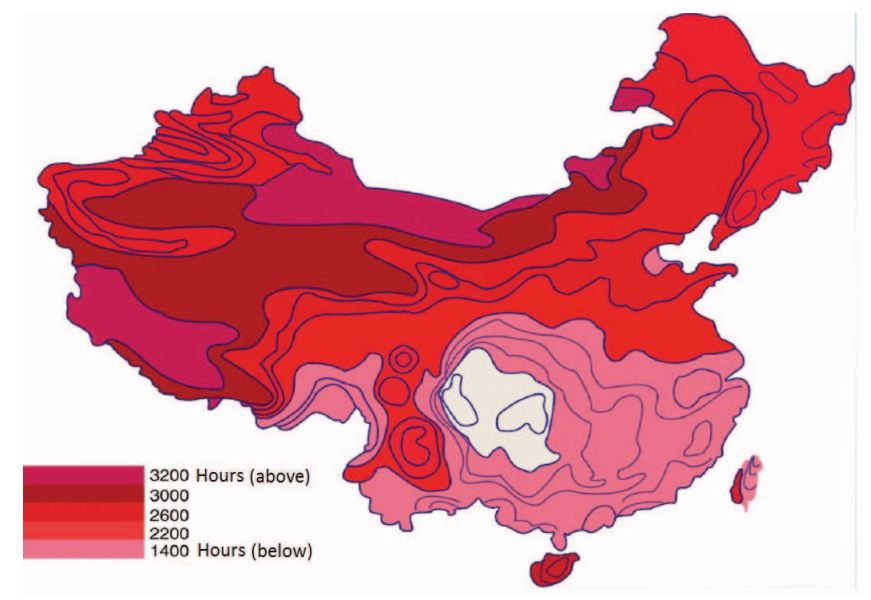

Figure 3: Solar power resources distribution in China

Biomass power boilers are typically in the 20-50 MW range, compared to coal-fired plants in the 100-1500 MW range. The small capacity plants tend to be lower in efficiency because of economic trade-offs; efficiency enhancing equipment cannot pay for itself in small plants. Although techniques exist to push biomass steam generation efficiency over $40 \%$, actual plant efficiencies are in the low $20 \%$ range. Modular systems employ some of these technologies but on a smaller scale that is more applicable to villages, farms, and small industry. These systems are now under development and could be most useful in remote areas where biomass is abundant and electricity is scarce. There are many opportunities for these systems in developing countries.

For wind energy, the permanent magnet generator is a synchronous machine where the rotor windings have been replaced with permanent magnets. This eliminates the excitation losses in the rotor, which otherwise typically represent $20 \%$ to $30 \%$ of the total generator losses. The reduced losses also give a lower temperature rise in the generator, which means that a smaller and simpler cooling system can be used. The temperature reduction in the rotor also reduces the temperature in the bearings, improving reliability by increasing the lifetime of the bearings and the bearing grease. The high efficiency of the generator means better utilization of the wind energy, producing more electrical power. The reduction in size and weight also makes the construction of the windmill easier as smaller lifting equipment can be used. Recent developments in permanent magnet generator technology have been made possible by a significant improvement of the magnetic materials during the past decade. A piece of neodymium boron iron $(\mathrm{NeFeB})$ material can have a magnetic force more than 10 times 
stronger than a traditional ferrite magnet. The establishment of renewables as the majority source of energy for electricity production has major implications on politics - from the local to the global levels. It has profound implications on power infrastructure and energy policies, and electricity generation business models.

From an energy security perspective, renewable energy sources like solar and wind are free and freely available around the globe. Fossil fuels have extraction and transportation costs, plus costs associated with protection and risk. Renewable energy sources have stable production costs, once the equipment is installed, the costs of operating and maintaining the equipment is very predictable. In contrast, fossil fuels have always demonstrated extreme price volatility that jeopardizes economies and countries. Renewable energy sources like solar and wind do not emit $\mathrm{CO} 2$, all fossil fuels do. Efforts to capture or sequester carbon create additional external costs that must be added into fossil fuel prices.

The National Action Plan includes increasing the proportion of electricity generation from renewable energy sources and from nuclear power, increasing the efficiency of coal-fired power stations, and the use of cogeneration. In January 2012, as part of its 12th Five-year Plan, China published a report 12th Five-year Plan on Greenhouse Emission Control, which establishes goals of reducing carbon intensity by $17 \%$ by 2015, compared with 2010 levels. In January 2012, the National Development and reform Commission also announced that Beijing, Tianjin, Shanghai, Chongqing and Shenzhen, and the provinces of Hubei and Guangdong participated in a pilot carbon cap and trade scheme that would operate in a similar way to the European Union Emission Trading Scheme. Consumers who purchase hybrid vehicles are eligible for an incentive that depends upon the type of vehicle and the difference in fuel economy in comparison to vehicles of similar weights. Homeowners who install solar electric systems, small wind systems or geothermal heat pumps can receive an incentive. It was planned that by 2020 non-fossil fuels in primary energy consumption will be around $15 \%$ and carbon dioxide emissions will decrease by $40 \%-45 \%$ as compared to that in 2005. To achieve above goals, it is necessary to develop clean energy.

Development and utilization of wind power is very important to the adjustment of energy structure, safeguard of energy security and promotion of energy conservation. With characteristics of intermittence, fluctuation and difficulty in scheduling, the development of wind power has a problem of utilization and development. When wind power has reached to a certain size, whether it can further enhance its development and utilization levels effectively with the necessary incentive policies and measures, it also depends on whether the grid infrastructure and other associated power system operation and management techniques are in place.

In addition to hydropower, wind power is currently the renewable energy that the technology is the most mature and the cost of production is relatively reasonable. However, in the current technical and economic conditions, it still does not have a good competition in the market. As a result, it is necessary for the government to promote wind power development incentive policy to provide the necessary protection and basic market earnings expectations for the investors.

It is necessary for large-scale development and utilization of wind power to connect to the grid. Since the basic features of the safe and stable operation of the power system is to achieve instantaneous response to changes in load demand through the effective control of power output. As wind power is a growing industry, it is important consider how to strengthen the policy incentives, while maintaining a balanced and orderly development, to avoid an increase in social costs.

With the large-scale rapid development of wind power, it is necessary to increase the pumped storage power plant construction to accelerate the development of energy storage for wind power and pumped storage coordination development. The expansion in renewables development and improvements in energy efficiency also provide new opportunities for technology trade and accelerating the transition toward a cleaner, less carbon-intensive energy mix.

Table 1 Common wind forecast types, methods and timeframe

\begin{tabular}{|c|c|c|}
\hline Forecast Types & Methods/Data used & Timeframe \\
\hline Short-term & $\begin{array}{l}\text { Statistical models } \\
\text { and recent wind } \\
\text { power production }\end{array}$ & Up to 8 hours \\
\hline Day-ahead & $\begin{array}{l}\text { Numerical weather } \\
\text { prediction (NWP) } \\
\text { forecast }\end{array}$ & Up to 4 days \\
\hline Long-term & NWP forecast & $\begin{array}{c}\text { Week ahead or } \\
\text { even month ahead }\end{array}$ \\
\hline Persistence & $\begin{array}{l}\text { Current wind power } \\
\text { production }\end{array}$ & $\begin{array}{l}\text { Next } 5 \text { to } 10 \\
\text { minutes }\end{array}$ \\
\hline Ramp & $\begin{array}{l}\text { Statistical models } \\
\text { and probabilistic } \\
\text { analysis }\end{array}$ & Up to 6 hours \\
\hline $\begin{array}{l}\text { Weather } \\
\text { situational }\end{array}$ & $\begin{array}{l}\text { Real-time weather } \\
\text { conditions, such as } \\
\text { wind speed is } \\
\text { greater than } \\
20 \mathrm{~m} / \mathrm{second}\end{array}$ & $\begin{array}{c}\text { Current } \\
\text { conditions }\end{array}$ \\
\hline
\end{tabular}

Table 1 shows several common wind forecast types, methods and timeframes. The purpose of the long range forecast is to get a general idea of wind generation production through the time period. There is no need to be precise but it provides expectations of high or low energy production. It can also be used to plan for scheduled generation and transmission outages.

Day-ahead wind generation forecast is used for unit commitment and reserves planning. It is also used to decide what thermal units are to be committed or de-committed after estimating how much wind energy could be produced. Because the forecast has to be submitted before the grid 
operator plan and set the day-ahead schedule, the wind generation forecast has to be two days ahead.

With increased wind generation in China, it is essential to determine how flexible the existing thermal units are and how they could match with wind energy generation accordingly.

Since China has an inflexible resource mix. China may have to rely upon two-day-ahead forecast to account for the speed to operation of its thermal plants. This means that wind energy forecast needs to be three days ahead.

Hour-ahead forecast covers the next several hours, or even days. Short-term forecast usually updated every 10 minutes. It is used to make changes in operation or dispatch decisions before real-time.

For wind forecasting, usually, large-scale NWP models are used to predict weather conditions. Local weather data is gathered to supplement the NWP models. If needed, statistical models are then used to account for influences of local terrain. In general, several forecasts are combined to form an 'Ensemble Forecast'.

Inflexible combined heat and power plants cause significant wind curtailment in China. Adding electric boilers and heat storage can reduce curtailment but the cost can be huge and a detailed analysis is needed to fully study the best way forward. Demand response with storage capabilities can reduce wind and solar PV curtailment but cost is also an issue. Gas turbines can help accommodating more wind energy into the power system. Currently fixed price is used in China and the market value of wind during different time periods cannot be reflected. Flexible electricity price is needed to unlock the potential of demand response and facilitate wind power priority dispatch.

Bilateral market, day-ahead market, intra-day market and real-time market are coordinated to ensure renewable energy priority dispatch. Wind power participates in different types of market with wind power forecasts, which are updated frequently, to ensure power balance and power system security.

Long-term and short-term unit commitments are combined to make generation schedules. In long-term unit commitment, limited information about wind power is used to provide rough plan of conventional generation. In short-term unit commitment, updated wind power forecast information is used to update generation schedules. A combination of longterm and short-term unit commitments helps integrating more wind energy into the system.

Nuclear power is a sustainable energy source that reduces carbon emission. In 2012, China had 15 nuclear power units with a total electric capacity of $11 \mathrm{GW}$ and total output of 54.8 billion $\mathrm{kWh}$, accounting for $1.9 \%$ country's total electricity output. This rose to 17 reactors in 2013. There are plans to increase nuclear power capacity and nuclear power percentage to $86 \mathrm{GW}$ and $4 \%$ respectively by 2020 . Plans are to increase this to $200 \mathrm{GW}$ and $400 \mathrm{GW}$ by 2030 and 2050 respectively. Nuclear power can be a controversial solution because of the danger that people associate with it, however, at present; China has 32 reactors under construction.

\section{CONCLUSIONS}

Keeping China competitive requires affordable energy. And here is a serious problem: China needs oil and gas, which are often imported from unstable parts of the world. The best way to break this need is through technology. China is investing more in zero-emission coal-fired plants; revolutionary solar and wind technologies; and clean nuclear energy.

There is a requirement to increase plant awareness, promotion of energy best practices; better justification of energy efficiency projects and innovative technology such as smart grid. Some novel strategies, approaches, challenges and opportunities have been discussed in the paper.

\section{ACKNOWLEDGMENTS}

Research in this paper is supported by the project, 'Novel Techniques and Their Applications for Development and Decision Support of Smart Distribution System', in State Grid Corporation of China. This support is very much appreciated.

\section{REFERENCES}

[1] Loi Lei Lai (Editor), Power System Restructuring and Deregulation: Trading, Performance and Information Technology, John Wiley \& Sons, UK, Sept 2001.

[2] L.L. Lai, S.W. Chan, P.K. Lee, and C.S. Lai, "Challenges to implementing distributed generation in area electric power system," 2011 IEEE International Conference on Systems, Man and Cybernetics.

[3] Loi Lei Lai and Tze Fun Chan, Distributed Generation Induction and Permanent Magnet Generator, Wiley and IEEE Press, October 2007.

[4] P.K. Lee, L.L. Lai and S.W. Chan, "A practical approach of energy efficiency management reporting systems in microgrid," 2011 IEEE Power \& Energy Society Annual Meeting.

[5] M. Tripathy, S. Mishra, L.L. Lai and Q.P. Zhang, "Transmission loss reduction based on FACTS and bacteria foraging algorithm," Lecture Notes in Computer Science, Springer-Verlag, 2006.

[6] http://www.iea.org/topics/smartgrids/ (Assessed on 11 Nov 2013)

[7] http://www.smartgridlibrary.com/tag/energy-security/ (Assessed on 11 Nov 2013)

[8] Manimegalai Sithan and Loi Lei Lai, "Application of green technologies in developing countries - reduced carbon emission and conservation of energy," 2011 IEEE Power \& Energy Society Annual Meeting.

[9] Draft Guide for Designing a Time Synchronization System for Power Substations, P2030.1017M/D1, IEEE, Nov. 2013. (Under consultation)

[10] Chun Sing Lai, "Compression of power system signals with wavelets," Proceedings of the International Conference on Wavelet Analysis and pattern Recognition, IEEE, Lanzhou China, July 2014.

[11] http://en.wikipedia.org/wiki/Energy_security_of_the_People $\% 2$ 7s_Republic_of_China (Assessed on 11 Nov 2013)

[12] http://www.iea.org/topics/energysecurity/ (Assessed on 11 Nov 2013)

[13] http://en.wikipedia.org/wiki/Energy_policy_of_China (Assessed on 11 Nov 2013) 